\title{
The Modified West China Hospital Radiographic Classification for Fibrous Dysplasia in Femur: A Retrospective Analysis of 238 Patients
}

\author{
Yitian Wang \\ Sichuan University West China Hospital \\ Li Min \\ Sichuan University West China Hospital \\ Yong Zhou \\ Sichuan University West China Hospital \\ Jie Wang \\ Sichuan University West China Hospital \\ Yuqi Zhang \\ Sichuan University West China Hospital \\ Minxun Lu \\ Sichuan University West China Hospital \\ Yi Luo \\ Sichuan University West China Hospital \\ Wenli Zhang \\ Sichuan University West China Hospital \\ Hong Duan \\ Sichuan University West China Hospital \\ chongqi tu ( $\nabla$ tuchongqibone@hotmail.com) \\ Sichuan University West China Hospital https://orcid.org/0000-0002-1045-9742
}

\section{Research article}

Keywords: Fibrous dysplasia, Radiograph, Classification, Treatment

Posted Date: November 23rd, 2020

DOI: https://doi.org/10.21203/rs.3.rs-104794/v1

License: (c) (7) This work is licensed under a Creative Commons Attribution 4.0 International License. Read Full License 


\begin{abstract}
Background: To investigate the reliability and clinical outcome of a newly developed classification system for patients, who had fibrous dysplasia (FD) in the femur.
\end{abstract}

Methods: A total of 238 patients with FD in the femur were included in this retrospective study. All affected femurs were measured and treated based on our classification. The intraobserver and interobserver reproducibility were assessed using the Cohen kappa statistic. The clinical outcome was evaluated using the criteria of Guille.

Results: At a median follow-up of 60 months, 238 patients were categorized into the following five types: type I to V. The interobserver and intraobserver kappa scores were excellent. For clinical outcomes, there was no significant difference in the postoperative Guille score between type I (mean $9.01 \pm 1.22$ ), II (mean $8.40 \pm 1.38$ ), and V (mean $8.47 \pm 1.69$ ). Type III and IV had significantly lower postoperative Guille scores than type I, II, and V. Moreover, type III had a significantly higher Guille score (mean $7.81 \pm 0.96$ ) than type IV (mean $6.57 \pm 2.09$ ).

Conclusion: Our classification is reproducible and provides a one-to-one correspondence between diagnosis and treatment. Therefore, we recommend this classification for the diagnosis and treatment of the FD in the femur.

\title{
Introduction
}

Fibrous dysplasia (FD) is a common skeletal disorder (monostotic or polyostotic) that results in pathological fractures, deformity, limping, and pain. FD is a benign intramedullary fibro-osseous lesion, which was first identified by Lichtenstein in 1938[1]. The mutation of the GNAS-gene decreases the GTPase activity of the stimulatory G-protein, which increased the intracellular levels of cyclic adenosine monophosphate (cAMP) and interleukin-6 (IL-6) secretion[2]. The increased intracellular cAMP content and increased IL- 6 secretion result in the increased numbers of osteoclasts and bone resorption. Primitive bone has failed to transform into the mature lamellar bone and realign in response to mechanical stress[3]. The lower extremity is frequently affected by deformity, fracture, leg length discrepancy (LLD), and limping[4-7]. Given the numerous surgical options and complicated deformities in the femur, it can be difficult for orthopedic surgeons to evaluate the severity of deformities and select an appropriate treatment strategy. Ippolito et al[8] have developed a classification system that characterizes femoral deformities of FD in six patterns, which only serve to guide the prediction of progression.

The surgical strategy is aimed at bone pain relief[9], restoring normal femoral alignment[5], gait normalization[6], LLD[5], and preventing pathological fracture $[4,10]$ for FD patients. Based on our early experience in assessing deformities and pairing treatment strategies[6, 11, 12], we modified our previous classification into five types following corresponding treatment options, which were as follows: including proximal femur bone loss, neck-shaft angle, femoral shaft deformity, genu valgum, and arthritis of hip. This study aimed to investigate the interobserver reliability and intraobserver reliability of our system and to evaluate the outcomes of surgical procedures based on our classification system that pair surgical strategy.

\section{Methods}

\section{Development of our classification system}

For radiographic analysis, the following features were determined in the lower extremity radiographs and axial computed tomography (CT) scans complex deformities based on standing limb alignment[13]: focal thinning of cortical bone and involvement of the calcar in the proximal femur, which measured on axial CT[14]; coxa vara, in which the neck-shaft angle was $\leq 120^{\circ}$; metaphyseal and femoral shaft deformity, in which varus or valgus malalignment was detected; genu valgum, in which the mechanical femorotibial angle was $\geq 10^{\circ}[15]$; hip arthritis, in which was detected according to the Kellgren Lawrence grading system[16].

\section{Radiographic Management}

Type I lesion was defined as none of the five features mentioned above. Type II lesion was defined as extensive bone loss of proximal femur (focal thinning of cortical bone and/or involvement of the calcar). Type III deformity included coxa vara and femoral shaft deformity, either alone or in combination. Additionally, hip internal or external rotation was measuring. Type IV deformity was characterized by severe genu valgum. And, type IV was to be alone or in combination with type III. Type V deformity was defined as any type associated with severe arthritis of the hip. For polyostotic FD patients involving the bilateral lower limbs, we record the severer side. To eliminate LLD, preoperative planning set the intact side (monostotic cases) or relatively short side (polyostotic cases) as standard. The opening- and closing-wedge osteotomy were provided for preventing LLD intraoperatively.

We retrospectively analyzed FD patients who were treated between January 2009 and January 2019 in our institution. Radiological diagnosis was made according to the features, including a grayish "ground-glass" appearance, endosteal scalloping, shepherd's crook deformity, and intramedullary expansible lesion with a smooth sclerotic margin[13]. Biopsy with histological evaluation was required in questionable cases and patients with a high suspicion of malignancy. All type II-V cases were histologically proven FD postoperatively. The study was approved by the Institutional Ethics Committee of West China Hospital (Chengdu, China), and the study protocol adhered to the guidelines stipulated in the World Medical Association Declaration of Helsinki.

\section{Perioperative Management}


For correspondence treatment of each type, type I was monitoring every 6 months[10]. And the indication for surgical treatment in type II-V patients included the following: mechanical/ weight-bearing bone pain, hip and/or knee stiff, walking with a limp, fracture, and severe LLD[10]. Therefore, type II was treated with internal fixation (IF) following simple curettage[4]. Type III was treated with the IF following single or multiple level valgus osteotomies and simple curettage[5, 6]. Type IV was treated with a high tibial osteotomy (HTO)[17] or distal femoral osteotomy (DFO)[18], following femoral malalignment correction. Type $\mathrm{V}$ was treated with total hip arthroplasty (THA) and lesion curettage[9], if necessary single-level valgus osteotomy was performed to fit femur stem[12] (Table 1)

Table 1

Radiographic Classification System of Fibrous Dysplasia in Femur

\begin{tabular}{|c|c|c|c|c|c|c|}
\hline Type & $\begin{array}{l}\text { Extensive bone loss of } \\
\text { proximal femur }\end{array}$ & $\begin{array}{l}\text { Coxa } \\
\text { vara }\end{array}$ & $\begin{array}{l}\text { Femoral shaft } \\
\text { deformity }\end{array}$ & $\begin{array}{l}\text { Genu } \\
\text { valgum }\end{array}$ & $\begin{array}{l}\text { Hip } \\
\text { arthritis }\end{array}$ & Intervention \\
\hline Type & - & - & - & - & - & Monitoring \\
\hline $\begin{array}{l}\text { Type } \\
\text { II }\end{array}$ & + & - & - & - & - & Curettage + IF \\
\hline $\begin{array}{l}\text { Type } \\
\text { III }\end{array}$ & $+/-$ & $+/-$ & $+/-$ & - & - & Curettage + Single/Multiple-level osteotomy + IF \\
\hline $\begin{array}{l}\text { Type } \\
\text { IV }\end{array}$ & $+/-$ & $+/-$ & $+/-$ & + & - & $\begin{array}{l}\text { Curettage }+ \text { Single/Multiple-level osteotomy }+ \text { IF }+ \\
\text { HTO or DFO }\end{array}$ \\
\hline $\begin{array}{l}\text { Type } \\
\text { V }\end{array}$ & $+/-$ & $+/-$ & $+/-$ & $+/-$ & + & THA +/- Single-level osteotomy \\
\hline \multicolumn{7}{|c|}{ IF, internal fixation; } \\
\hline \multicolumn{7}{|c|}{ THA, total hip arthroplasty } \\
\hline
\end{tabular}

Type I patients followed up with a semi-annual assessment. Early weight-bearing protocols varied in type II-IV. Type II patients were allowed full weight-bearing immediately after surgery. Type III and IV patients were allowed toe-touch weight-bearing within 6 weeks, and partial weight-bearing at $6-12$ weeks postoperatively. Then progressive weight-bearing was permitted thereafter[19]. For type $\mathrm{V}$ patients who underwent valgus osteotomy, the weight-bearing protocol was the same as that of type III and IV. Without valgus osteotomy, the protocol of type V patients was the same as that for type II patients[12].

\section{Agreement Analysis}

In the specialist group, the mean interobserver and intraobserver kappa scores were 0.85 (range $0.80-0.89)$ and 0.87 (0.79-0.92), respectively. In the resident group, the mean interobserver and intraobserver kappa scores were 0.80 (range $0.77-0.81$ ) and $0.83(0.80-0.84)$, respectively. In total, the mean interobserver and intraobserver kappa scores were 0.85 (range $0.77-0.89$ ) and 0.85 (0.79-0.92), respectively. The highest percentage of erroneous classification was observed in types I and II.

\section{Results}

\section{Classification of our population}

A total of 238 patients with FD in the femur were enrolled in our institution. Of the included 238 patients, 168 had monostotic FD and 70 had polyostotic FD. All femurs could be categorized by our radiographic classification. The classification including five types of FD was noted (Table 2). 
Table 2

Patient Characteristics*

\begin{tabular}{|ll|}
\hline & No. of Patients (\%) \\
\hline Age (years) & median 29 (range 7.1-73) \\
\hline Gender & $141(59.2)$ \\
\hline Female & $97(40.8)$ \\
\hline Male & \\
\hline Category & $168(70.6)$ \\
\hline Monostotic & $70(29.4)$ \\
\hline Polyostotic & \\
\hline Prevalence of different types & 82(34.5) \\
\hline Type I & $72(30.3)$ \\
\hline Type II & $48(20.2)$ \\
\hline Type III & $21(8.8)$ \\
\hline Type IV & $15(6.3)$ \\
\hline Type V & \\
\hline Follow-up (months) & median 60 (range 6-120) \\
\hline Total & median 63 (range 6-120) \\
\hline Type I & median 48 (range 12-120) \\
\hline Type II & median 72 (range 60-120) \\
\hline Type III & \\
\hline Type IV & \\
\hline Type V & \\
\hline *N = 238 patients (250 affected femurs) \\
\hline
\end{tabular}

\section{Clinical Outcome}

At a median follow-up of 60 months (range 6-120 months), all patients were evaluated using the criteria of Guille et al[6, 21]. With regards to the variations of functional outcomes before and after surgery, there was a significant increase in the postoperative Guille score in types II-V, compared to the preoperative values. In type I, there was no significant difference between the initial and latest assessments. As for the postoperative Guille score, there was no significant difference among type I (mean $9.01 \pm 1.22$ ), II (mean $8.40 \pm 1.38$ ), and V (mean 8.47 \pm 1.69 ) cases. Type III and IV cases were significantly lower postoperatively Guille score than type I, II, and V. Moreover, type III cases had significantly higher Guille score (mean $7.81 \pm 0.96)$ than type IV cases (mean $6.57 \pm 2.09$ ) (Table 3). 
Table 3

Preoperative/postoperative clinical scores evaluated by the modified criteria of Guille

\begin{tabular}{|c|c|c|c|c|c|c|c|c|c|c|c|c|c|c|}
\hline \multirow[t]{2}{*}{ Categories } & \multicolumn{4}{|c|}{ Type II(n= 72) } & \multicolumn{4}{|c|}{ Type III(n= 48) } & \multicolumn{4}{|c|}{ Type IV(n = 21) } & \multicolumn{2}{|c|}{ Type V(n= 1} \\
\hline & $\begin{array}{l}U^{*} \\
(n)\end{array}$ & $A^{*}(n)$ & $S^{*}(n)$ & $\begin{array}{l}\text { Mean } \\
\text { score }\end{array}$ & $\begin{array}{l}U^{*} \\
(n)\end{array}$ & $\begin{array}{l}A^{*} \\
(n)\end{array}$ & $\begin{array}{l}S^{*} \\
(n)\end{array}$ & $\begin{array}{l}\text { Mean } \\
\text { score }\end{array}$ & $\begin{array}{l}U^{*} \\
(n)\end{array}$ & $\begin{array}{l}A^{*} \\
(n)\end{array}$ & $\begin{array}{l}S^{*} \\
(n)\end{array}$ & $\begin{array}{l}\text { Mean } \\
\text { score }\end{array}$ & $\begin{array}{l}U^{*} \\
(n)\end{array}$ & $\begin{array}{l}A^{*} \\
(n)\end{array}$ \\
\hline Pain & $49 / 1$ & $23 / 14$ & $0 / 57$ & $\begin{array}{l}0.32 \pm \\
0.47 / 1.78 \\
\pm 0.45\end{array}$ & $46 / 2$ & $2 / 12$ & $0 / 34$ & $\begin{array}{l}0.13 \pm \\
0.33 / 1.67 \\
\pm 0.56\end{array}$ & $16 / 2$ & $5 / 7$ & $0 / 12$ & $\begin{array}{l}0.24 \pm \\
0.44 / 1.48 \\
\pm 0.68\end{array}$ & $15 / 2$ & $0 / 1$ \\
\hline $\begin{array}{l}\text { Hip } \\
\text { motion }\end{array}$ & $22 / 2$ & $38 / 24$ & $12 / 46$ & $\begin{array}{l}0.86 \pm \\
0.68 / 1.61 \\
\pm 0.55\end{array}$ & $39 / 0$ & $9 / 21$ & $0 / 27$ & $\begin{array}{l}0.19 \pm \\
0.39 / 1.56 \\
\pm 0.50\end{array}$ & $10 / 3$ & $10 / 8$ & $1 / 10$ & $\begin{array}{l}0.67 \pm \\
0.66 / 1.33 \\
\pm 0.73\end{array}$ & $15 / 0$ & $0 / 4$ \\
\hline Limping & $43 / 0$ & $10 / 19$ & $19 / 53$ & $\begin{array}{l}0.67 \pm \\
0.87 / 1.74 \\
\pm 0.44\end{array}$ & $41 / 1$ & $3 / 22$ & $4 / 25$ & $\begin{array}{l}0.23 \pm \\
0.59 / 1.50 \\
\pm 0.55\end{array}$ & $10 / 2$ & $5 / 11$ & $6 / 8$ & $\begin{array}{l}0.81 \pm \\
0.87 / 1.29 \\
\pm 0.64\end{array}$ & $13 / 1$ & $2 / 4$ \\
\hline $\begin{array}{l}\text { Activities } \\
\text { of daily } \\
\text { living }\end{array}$ & $51 / 0$ & $6 / 21$ & $15 / 51$ & $\begin{array}{l}0.50 \pm \\
0.82 / 1.71 \\
\pm 0.46\end{array}$ & $45 / 1$ & $2 / 18$ & $1 / 29$ & $\begin{array}{l}0.83 \pm \\
0.35 / 1.58 \\
\pm 0.54\end{array}$ & $9 / 0$ & $9 / 12$ & $3 / 9$ & $\begin{array}{l}0.71 \pm \\
0.72 / 1.43 \\
\pm 0.51\end{array}$ & $12 / 0$ & $3 / 2$ \\
\hline $\begin{array}{l}\text { Social } \\
\text { activities }\end{array}$ & $56 / 1$ & $9 / 29$ & $7 / 42$ & $\begin{array}{l}0.32 \pm \\
0.65 / 1.57 \\
\pm 0.53\end{array}$ & $47 / 2$ & $1 / 20$ & $0 / 26$ & $\begin{array}{l}0.21 \pm \\
1.44 / 1.50 \\
\pm 0.58\end{array}$ & $12 / 3$ & $9 / 14$ & $0 / 4$ & $\begin{array}{l}0.43 \pm \\
0.51 / 1.05 \\
\pm 0.59\end{array}$ & $15 / 1$ & $0 / 4$ \\
\hline Total & & & & $\begin{array}{l}2.67 \pm \\
2.44 / 8.40 \\
\pm 1.38\end{array}$ & & & & $\begin{array}{l}0.65 \pm \\
0.98 / 7.81 \\
\pm 0.96\end{array}$ & & & & $\begin{array}{l}2.86 \pm \\
1.98 / 6.57 \\
\pm 2.09\end{array}$ & & \\
\hline
\end{tabular}

$* \mathrm{U}=$ unsatisfactory, $\mathrm{A}=$ average, and $\mathrm{S}=$ satisfactory. Clinical outcomes were scored as 0 (unsatisfactory), 1 (average), or 2 (satisfactory). For a potential max points, $>9$ points were defined as excellent, 7 or 8 points as good, 5 or 6 points as fair, and $<5$ points as poor.

For complications, two type III patients still complained of pain, one type III patients had mild-to-moderate Trendelenburg gait. One type IV patients had a mild Trendelenburg gait. And two type $\mathrm{V}$ patients still had mild limping.

\section{Discussion}

This study provides a framework for the systematic evaluation and management of the FD-induced-deformity. The spectrum of femoral deformities in fulllength was classified into five categories. Furthermore, their corresponding management was recommended. Currently, there have been only two prior systematic categories $[8,11]$, which classify a variety of proximal femoral deformities in FD. However, both classifications were failed to guide the most appropriate strategy for treatment. In Ippolito et al's[8] study, three orthopedic surgeons and one pathologist evaluated FD femurs on two occasions with an interval of 6 weeks. The intraobserver (0.855) and interobserver (range, 0.833-0.871) agreement were both excellent. The highest percentage of mistakes was made when distinguishing mild shepherd's crook deformity from severe shepherd's crook deformity. In our primary classification system[11], two senior orthopedic surgeons evaluated the cases for two rounds with a 6-week interval. The intraobserver and interobserver agreements were both excellent. In this study, the mean interobserver and intraobserver kappa scores were 0.85 (range $0.77-0.89)$ and $0.85(0.79-0.92)$, respectively. Although the agreement was excellent, the dispute was focused on the genu valgum between types III and IV. In some of the type IV lesions, genu valgum secondary to the restoration of the normal femoral alignment was remarkable after valgus osteotomy. Therefore, the surgeon must be prepared to manage the genu valgum in some type IV patients. Moreover, we recommend classifying these patients into type IV for correspondence surgical options (Fig. 1).

Type I lesions have no focal thinning of cortical bone and involvement of the calcar in the proximal femur, and we recommend conservative treatment with monitoring every 6 months (Fig. 2). Bone pain in FD should be discreetly assessed. Focal or weight-bearing pain may indicate an imminent or impending fracture[22]. Physiotherapy and pain medication can be administered, including opioids and non-steroidal anti-inflammatory drugs[10]. Besides, intravenous bisphosphonate is proposed for persistent, moderate to severe pain, even in children and adolescents[23, 24]. Moreover, denosumab, targeting RANKL that is expressed by osteogenic cells, maybe a potential treatment for bone pain caused by FD[25]. During follow-up, no severe complications were detected in type I patients.

Type II lesions are characterized by focal thinning of cortical bone and/or involvement of the calcar, without other femoral deformities. Type II patients often have mechanical or weight-bearing bone pain, which is a signal of stress or an impending fracture[10, 26]. Therefore, curettage, bone graft, and internal IF are recommended (Fig. 3). The efficacy and complications of bone graft are still controversial[10, 27]. However, cortical allografts were still recommended for the final and slow internal replacement by the host bone, especially in monostotic FD patients[3,5]. The intramedullary lesion should be adequately bridged by IF including dynamic hip screw (DHS), anatomical plate, or intramedullary nail[4, 28, 29]. In our study, only one type II patients had mild-to-moderate pain postoperatively.

Type III patients refer to the deformity of coxa vara and/or femoral shaft deformity associated with bone pain. For the single-level osteotomy site, the subtrochanteric region[5, 6, 30] (Fig. 4) and the dome of the deformity[6, 31, 32](Fig. 5) were recommended. However, the double-level osteotomy is strongly considered inadequate for correcting severe deformity [6, 31, 33]. After osteotomy, orderly curettage, massive impaction allograft, and IF are performed[4, 34, 35]. The choice of IF is still controversial. Previously, some authors suggested the longer DHS rather than intramedullary nailing, because of its ability in correcting varus and rotational deformities of the femoral neck and simplify procedure[5, 30, 32]. However, some studies report that intramedullary nails can provide good biomechanical support[6,34]. In general, we recommend intramedullary nail for the following reasons. Firstly, it provides sufficient stability that 
prevents stress fracture and screw loosening or pullout, especially in polyostotic FD patients[5, 29]. Secondly, it accommodates multiple-level osteotomy[31]. To increase the initial stability, the transversal surface of the femur after osteotomy should be entirely matched for locking each other. Additionally, the intramedullary lesions with sclerotic rim have sufficient bone mass, which provides adequate stability for nail fixation. Therefore, the sclerotic bone should be discreetly preserved when curettage and reaming canal. Moreover, rotational deformities of the femur could be gradually corrected. In our study, two type III cases still complained of pain, remained pain, owing to mild hip joint degeneration. One type III patient had mild-to-moderate Trendelenburg gait.

Preoperatively, the neck-shaft angle of this patient was only $75^{\circ}$. Over-tensioning of the gluteus medius was inevitable postoperatively after the correction of coxa vara[36].

Type IV are detected in patients with severe genu valgum. When combined with type III deformity, a two-stage treatment was recommended. Complex femoral deformities and lesion curettage were corrected firstly. After six months of rehabilitation, the second-stage procedure was performed for patients, who still complained of typical symptoms. We suggest HTO or DFO, for achieving a satisfactory appearance, correcting limb alignment, and relieving pain[18, 37]. However, for polyostotic FD patients, genu valgum is mainly caused by the proximal tibia and distal femur; thus, DFO and HTO are both recommended (Figs. 6 and 7). Type IV lesions are uncommon and the most challenging type and patients with this type of deformity have a lower Guille score, compared to other types of patients. In our study, only one type IV patient had mild Trendelenburg gait, because of the over-tensioning of the gluteus medius.

Type V lesions are found in FD patients with severe hip arthritis, combined with other types (II/III/IV). The deformities of the femoral shaft, coxa vara, and genu valgum, are significantly associated with the degeneration of the hip and knee. Additionally, polyostotic FD is found to be more prevalent in hip arthritis than monostotic FD[38, 39]. In our study, type $V$ patients had significantly higher Guille scores than type III and IV, but no significant difference was found between patients with type $\mathrm{V}$ and those types I and II. Although a small fraction of FD patients with mild deformity may be classified into type $\mathrm{V}$, the relatively high Guille score was preliminary evidence to guide treatment. Sierra et al.[9] firstly reported THA in patients with FD. When hip arthritis has been severe enough, total hip arthroplasty is suggested. Furthermore, a cemented stem was suggested to have a lower revision rate than an uncemented stem. However, our institution reported that the long uncemented stem showed reliable fixation at mid-term follow up[12], using Mimics V17.0 Software (Materialise Corp. Belgium), precise preoperative planning, and simulation of the osteotomy. Also, implantation of the prosthesis stem in a three-dimensional reconstructive model is essential. For the femoral component, we recommend fully coated stems, which engage in normal diaphyseal bone bypassing the lesion areas at least 2 femoral canal diameters to decrease the risk of postoperative fractures[9] (Figs. 8 and 9). The stem implantation is a crucial point. First, precision osteotomy was assisted by a patient-specific instrument, using a micropendulum saw. Second, the femoral cavity was temporarily fixed after thoroughly evacuation and bone graft. Third, the femur was reamed following addressing the greater trochanter. Two type $\mathrm{V}$ patients had mild limping, because of leg length discrepancy after THA.

There were several limitations to our study. Firstly, the classification was retrospective and confined to radiographic images. Secondly, the follow-up time was significantly different among the five groups. Thus, multicenter studies with a longer follow-up time are needed to make sufficient conclusions on our classification, especially for type V. Thirdly, surgical strategies and classifications are appropriate only for adult patients since most patients in our department were adults (median age 29 years, range 7.1-73 years). Finally, although many patients firstly visited the surgical department due to a pathologic fracture, we have treated some patients with conditions that may not be classified by our system.

\section{Conclusions}

We developed a new classification system for FD in the femur which was built on a review of the literature and clinical outcomes. Agreement analysis of the classification of our population showed that our classification system is reproducible, and clinically directed for standardizing the surgical treatment for these deformities. Moreover, follow-up evaluations showed pain relief and gait improvement in most patients. We believe that our classification system provides a one-to-one correspondence between diagnosis and treatment. Therefore, we recommend this classification for the diagnosis and treatment of the FD in the femur.

\section{Abbreviations}

FD: fibrous dysplasia; CAMP: cyclic adenosine monophosphate; IL-6: interleukin-6; LLD: leg length discrepancy; CT: computed tomography; IF: internal fixation; HTO: high tibial osteotomy; DFO: distal femoral osteotomy; THA: total hip arthroplasty; DHS: dynamic hip screw.

\section{Declarations}

\section{Acknowledgements}

We are thankful for the support of the nurse team from the Department of Orthopedics, West China Hospital. We are thankful for the patients enrolled in this study.

And we thank Xianliang Zhang M.D (Department of pathology, West China Hospital) for pathology evaluation.

\section{Authors' contributions}

TYW, LM, and CQT were involved with the concept and design of this manuscript. YZ,TYW, WLZ and DH were involved with the acquisition of subjects and data. MXL, JW, YQZ, YL, and CQT were involved in the perioperative management. YTW, LM and CQT were involved in postsurgical evaluation of the patients. All authors contributed toward data analysis, drafting and critically revising the paper, gave final approval of the version to be published, and agree to be accountable for all aspects of the work. All 
authors read and approved the final manuscript.

\section{Funding}

This work was supported, in part, by the National Key Research and Development Program of China (No. 2016YFC1102003, Dr. Tu), and the Science and Technology Research Program of Sichuan Province (No. 2020YFS0036, Dr. Tu); the Chengdu Science and Technology Program Projects (No. 2017-CY0200032-GX, Dr. Zhou) and the National Natural Science Foundation of China (No. 81801852, Dr. Zhou); the National Key Research and Development Program of China (No. 2017YFB0702604, Dr. Min).

\section{Availability of data and materials}

The datasets used and analyzed during the current study are available from the corresponding author on reasonable request.

\section{Ethics approval and consent to participate}

This study was approved and monitored by the Ethical Committee of West China Hospital, Sichuan University in China (No.2019342). All patients signed the informed consent.

\section{Consent for publication}

Written informed consent was obtained from all patients for publication of this study and any accompanying images.

\section{Competing interests}

The authors report no competing interest in this work.

\section{References}

1. Lichtenstein L, Jaffe HL. Fibrous dysplasia of bone - A condition affecting one, several or many bones the graver cases of which may present abnormal pigmentation of skin premature sexual development hyperthyroidism or skill other extraskeletal abnormalities. Archives of Pathology. 1942;33(6):777816.

2. Weinstein LS, Shenker A, Gejman PV, Merino MJ, Friedman E, Spiegel AM. Activating mutations of the stimulatory G protein in the McCune-Albright syndrome. N Engl J Med. 1991;325(24):1688-95.

3. DiCaprio MR, Enneking WF. Fibrous dysplasia. Pathophysiology, evaluation, and treatment. J Bone Joint Surg Am. 2005;87(8):1848-64.

4. Majoor BCJ, Leithner A, van de Sande MAJ, Appelman-Dijkstra NM, Hamdy NAT, Dijkstra PDS. Individualized approach to the surgical management of fibrous dysplasia of the proximal femur. Orphanet J Rare Dis. 2018;13(1):72.

5. Ippolito E, Farsetti P, Valentini MB, Potenza V. Two-stage surgical treatment of complex femoral deformities with severe coxa vara in polyostotic fibrous dysplasia. J Bone Joint Surg Am. 2015;97(2):119-25.

6. Yang L, Jing Y, Hong D, Chong-Qi T. Valgus osteotomy combined with intramedullary nail for Shepherd's crook deformity in fibrous dysplasia: 14 femurs with a minimum of 4 years follow-up. Arch Orthop Trauma Surg. 2010;130(4):497-502.

7. Han I, Choi ES, Kim HS. Monostotic fibrous dysplasia of the proximal femur: natural history and predisposing factors for disease progression. Bone Joint J. 2014;96-B(5):673-6.

8. Ippolito E, Farsetti P, Boyce AM, Corsi A, De Maio F, Collins MT. Radiographic classification of coronal plane femoral deformities in polyostotic fibrous dysplasia. Clin Orthop Relat Res. 2014;472(5):1558-67.

9. Sierra RJ, Cabanela ME. Total hip arthroplasty in patients with underlying fibrous dysplasia. Orthopedics. 2009;32(5):320.

10. Javaid MK, Boyce A, Appelman-Dijkstra N, Ong J, Defabianis P, Offiah A, Arunde P, Shaw N, Pos VD, Underhil A, et al. Best practice management guidelines for fibrous dysplasia/McCune-Albright syndrome: a consensus statement from the FD/MAS international consortium. Orphanet $\mathrm{J}$ Rare Dis. 2019;14(1):139.

11. Zhang X, Chen C, Duan H, Tu C. Radiographic classification and treatment of fibrous dysplasia of the proximal femur: 227 femurs with a mean follow-up of 6 years. J Orthop Surg Res. 2015;10:171.

12. Yao K, Min L, Tang F, Lu M, Zhang Y, Wang J, Zhou Y, Luo Y, Zhang W, Tu C. First application of three-dimensional designing total hip arthroplasty with long uncemented stem for fibrous dysplasia patients combined with hip joint osteoarthritis. BMC Musculoskelet Disord. 2019;20(1):222.

13. Fitzpatrick KA, Taljanovic MS, Speer DP, Graham AR, Jacobson JA, Barnes GR, Hunter TB. Imaging findings of fibrous dysplasia with histopathologic and intraoperative correlation. AJR Am J Roentgenol. 2004;182(6):1389-98.

14. Treece GM, Poole KE, Gee AH. Imaging the femoral cortex: thickness, density and mass from clinical CT. Med Image Anal. 2012;16(5):952-65.

15. Babis GC, An KN, Chao EY, Rand JA, Sim FH. Double level osteotomy of the knee: a method to retain joint-line obliquity. Clinical results. J Bone Joint Surg Am. 2002;84-A(8):1380-8.

16. Jacobson JA, Girish G, Jiang Y, Sabb BJ. Radiographic evaluation of arthritis: degenerative joint disease and variations. Radiology. 2008;248(3):737-47.

17. Chiba K, Yonekura A, Miyamoto T, Osaki M, Chiba G. Tibial condylar valgus osteotomy (TCVO) for osteoarthritis of the knee: 5-year clinical and radiological results. Arch Orthop Trauma Surg. 2017;137(3):303-10.

18. Wang JW, Hsu CC. Distal femoral varus osteotomy for osteoarthritis of the knee. J Bone Joint Surg Am. 2005;87(1):127-33. 
19. Kubiak EN, Beebe MJ, North K, Hitchcock R, Potter MQ. Early weight bearing after lower extremity fractures in adults. J Am Acad Orthop Surg. 2013;21(12):727-38.

20. Landis JR, Koch GG. The measurement of observer agreement for categorical data. Biometrics. 1977;33(1):159-74.

21. Guille JT, Kumar SJ, MacEwen GD. Fibrous dysplasia of the proximal part of the femur. Long-term results of curettage and bone-grafting and mechanical realignment. J Bone Joint Surg Am. 1998;80(5):648-58.

22. Majoor BCJ, Traunmueller E, Maurer-Ertl W, Appelman-Dijkstra NM, Fink A, Liegl B, Hamdy NAT, Sander Dijkstra PD, Leithner A. Pain in fibrous dysplasia: relationship with anatomical and clinical features. Acta Orthop. 2019;90(4):401-5.

23. Majoor BC, Appelman-Dijkstra NM, Fiocco M, van de Sande MA, Dijkstra PS, Hamdy NA. Outcome of Long-Term Bisphosphonate Therapy in McCuneAlbright Syndrome and Polyostotic Fibrous Dysplasia. J Bone Miner Res. 2017;32(2):264-76.

24. Boyce AM, Tosi LL, Paul SM. Bisphosphonate treatment for children with disabling conditions. PM R: the journal of injury function rehabilitation. 2014;6(5):427-36.

25. Benhamou J, Gensburger D, Chapurlat R. Transient improvement of severe pain from fibrous dysplasia of bone with denosumab treatment. Joint Bone Spine. 2014;81(6):549-50.

26. Majoor BC, Peeters-Boef MJ, van de Sande MA, Appelman-Dijkstra NM, Hamdy NA, Dijkstra PD. What Is the Role of Allogeneic Cortical Strut Grafts in the Treatment of Fibrous Dysplasia of the Proximal Femur? Clin Orthop Relat Res. 2017;475(3):786-95.

27. Grzegorzewski A, Pogonowicz E, Sibinski M, Marciniak M, Synder M. Treatment of benign lesions of humerus with resection and non-vascularised, autologous fibular graft. Int Orthop. 2010;34(8):1267-72.

28. Stanton RP, Ippolito E, Springfield D, Lindaman L, Wientroub S, Leet A. The surgical management of fibrous dysplasia of bone. Orphanet J Rare Dis. 2012;7(Suppl 1):1.

29. Kataria H, Sharma N, Kanojia RK. One-stage osteotomy and fixation using a long proximal femoral nail and fibular graft to correct a severe shepherd's crook deformity in a patient with fibrous dysplasia: a case report. J Orthop Surg. 2009;17(2):245-7.

30. Li W, Huang X, Ye Z, Yang D, Tao H, Lin N, Yang Z. Valgus osteotomy in combination with dynamic hip screw fixation for fibrous dysplasia with shepherd's crook deformity. Arch Orthop Trauma Surg. 2013;133(2):147-52.

31. Chen F, Wei Y, Xia J, Wu J, Wang S, Huang G, Chen J, Shi J. Double-level osteotomy and one-stage reconstruction with long intramedullary femoral nail to correct a severe proximal and diaphyseal femur deformity in a patient with polyostotic fibrous dysplasia: case report and literatures review. Int $\mathrm{J}$ Clin Exp Med. 2015;8(8):14188-95.

32. Tong Z, Zhang W, Jiao N, Wang K, Chen B, Yang T. Surgical treatment of fibrous dysplasia in the proximal femur. Exp Ther Med. 2013;5(5):1355-8.

33. Jung ST, Chung JY, Seo HY, Bae BH, Lim KY. Multiple osteotomies and intramedullary nailing with neck cross-pinning for shepherd's crook deformity in polyostotic fibrous dysplasia: 7 femurs with a minimum of 2 years follow-up. Acta Orthop. 2006;77(3):469-73.

34. Zhang X, Shang X, Wang Y, He R, Shi G. Intramedullary nailing for fibrous dysplasia of lower limbs. Oncol Lett. 2012;4(3):524-8.

35. Wan J, Zhang C, Liu YP, He HB. Surgical treatment for shepherd's crook deformity in fibrous dysplasia: THERE IS NO BEST, ONLY BETTER. Int Orthop. 2019;43(3):719-26.

36. Ippolito E, Valentini MB, Lala R, De Maio F, Sorge R, Farsetti P. Changing Pattern of Femoral Deformity During Growth in Polyostotic Fibrous Dysplasia of the Bone: An Analysis of 46 Cases. J Pediatr Orthop. 2016;36(5):488-93.

37. Saithna A, Kundra R, Modi CS, Getgood A, Spalding T. Distal femoral varus osteotomy for lateral compartment osteoarthritis in the valgus knee. A systematic review of the literature. The open orthopaedics journal. 2012;6:313-9.

38. Kim HS, Im SB, Han I. Osteoarthritis of the hip in fibrous dysplasia of the proximal femur. Bone Joint J. 2015;97-B(7):1007-11.

39. Paul SM, Gabor LR, Rudzinski S, Giovanni D, Boyce AM, Kelly MR, Collins MT. Disease severity and functional factors associated with walking performance in polyostotic fibrous dysplasia. Bone. 2014;60:41-7.

\section{Figures}




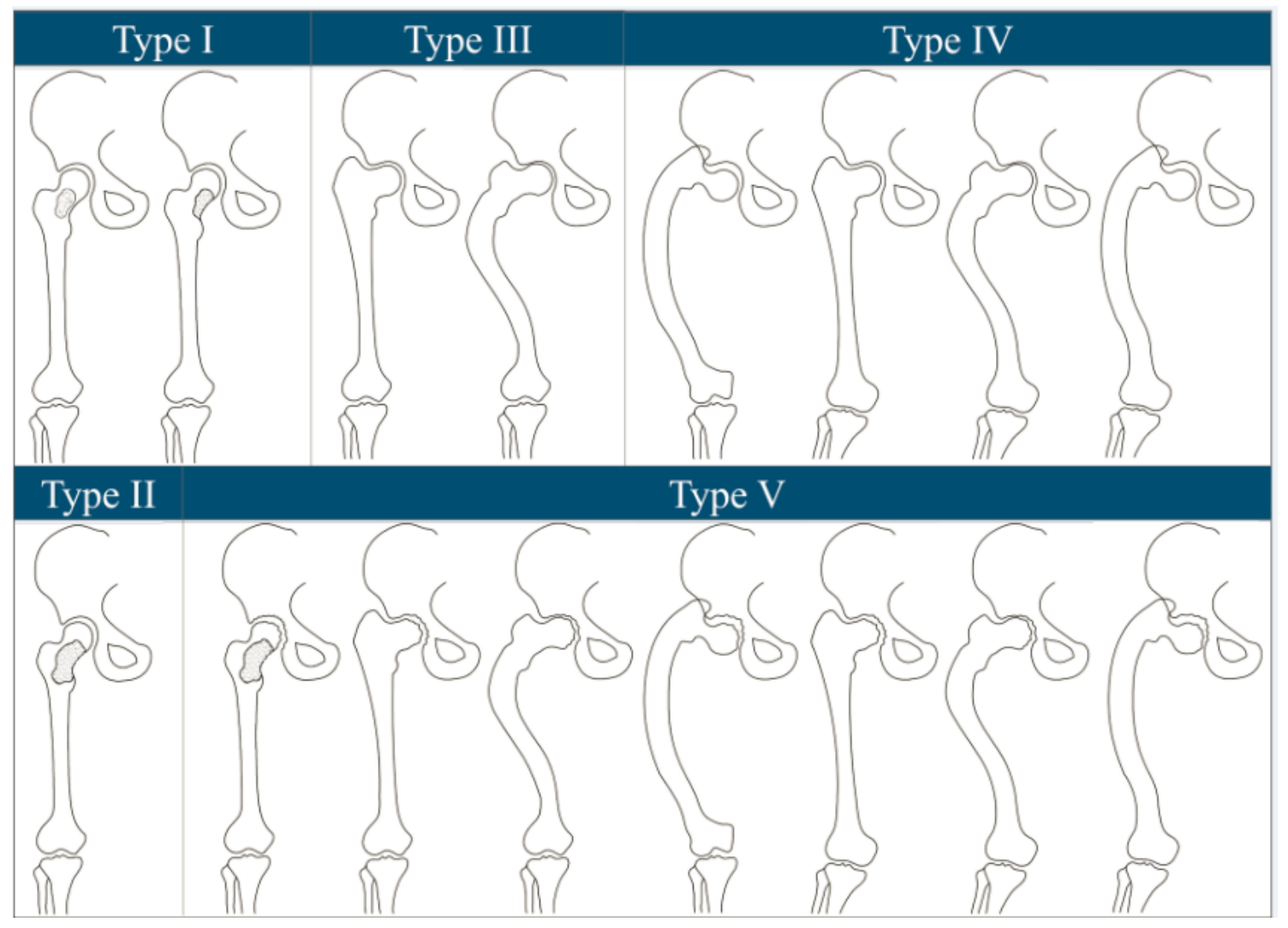

Figure 1

The classification is indicated by Roman numerals, starting with I and ending with V. Type III, IV, and V have three subtypes (A, B, and C).

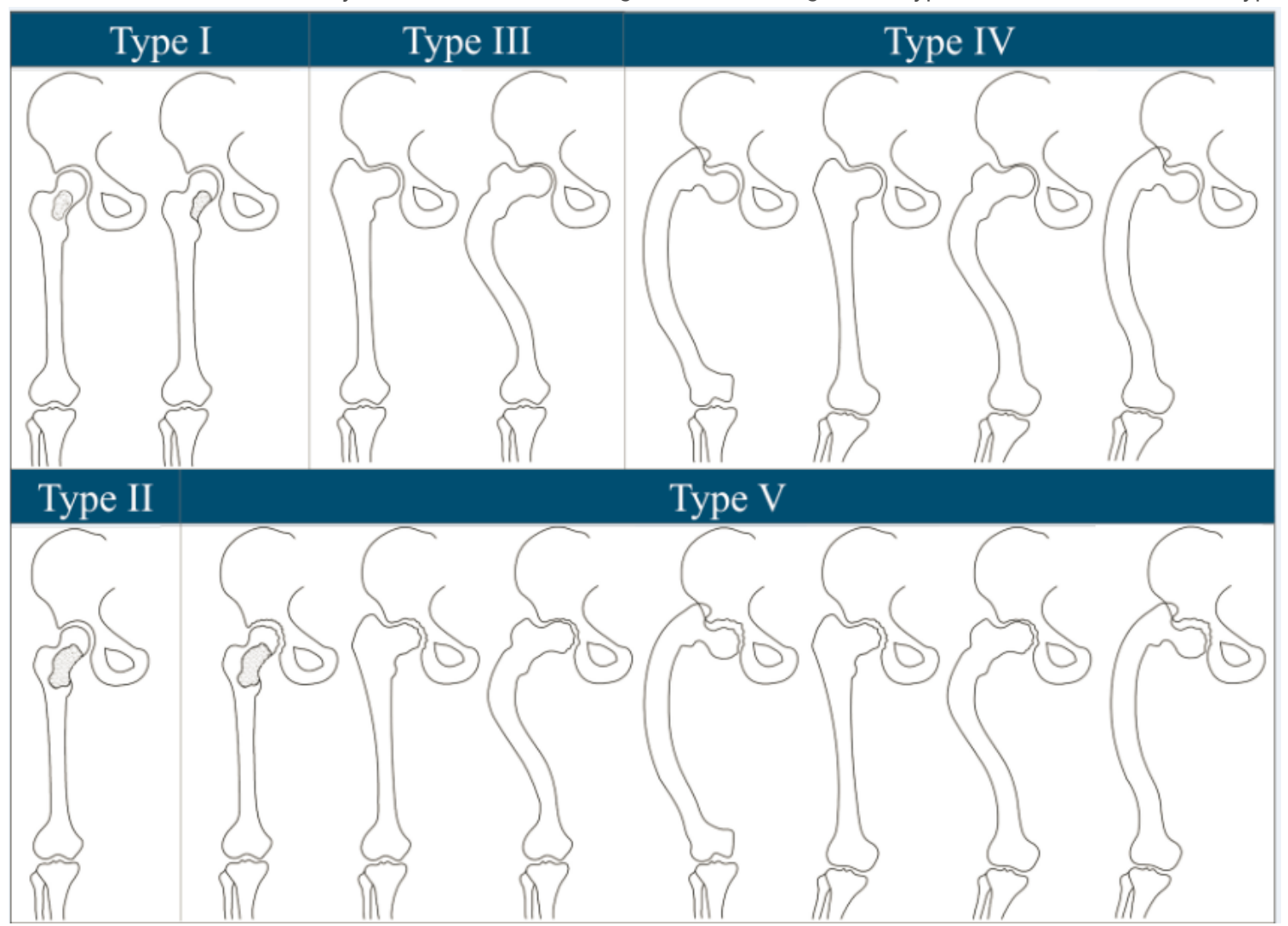

Figure 1

The classification is indicated by Roman numerals, starting with I and ending with V. Type III, IV, and V have three subtypes (A, B, and C). 

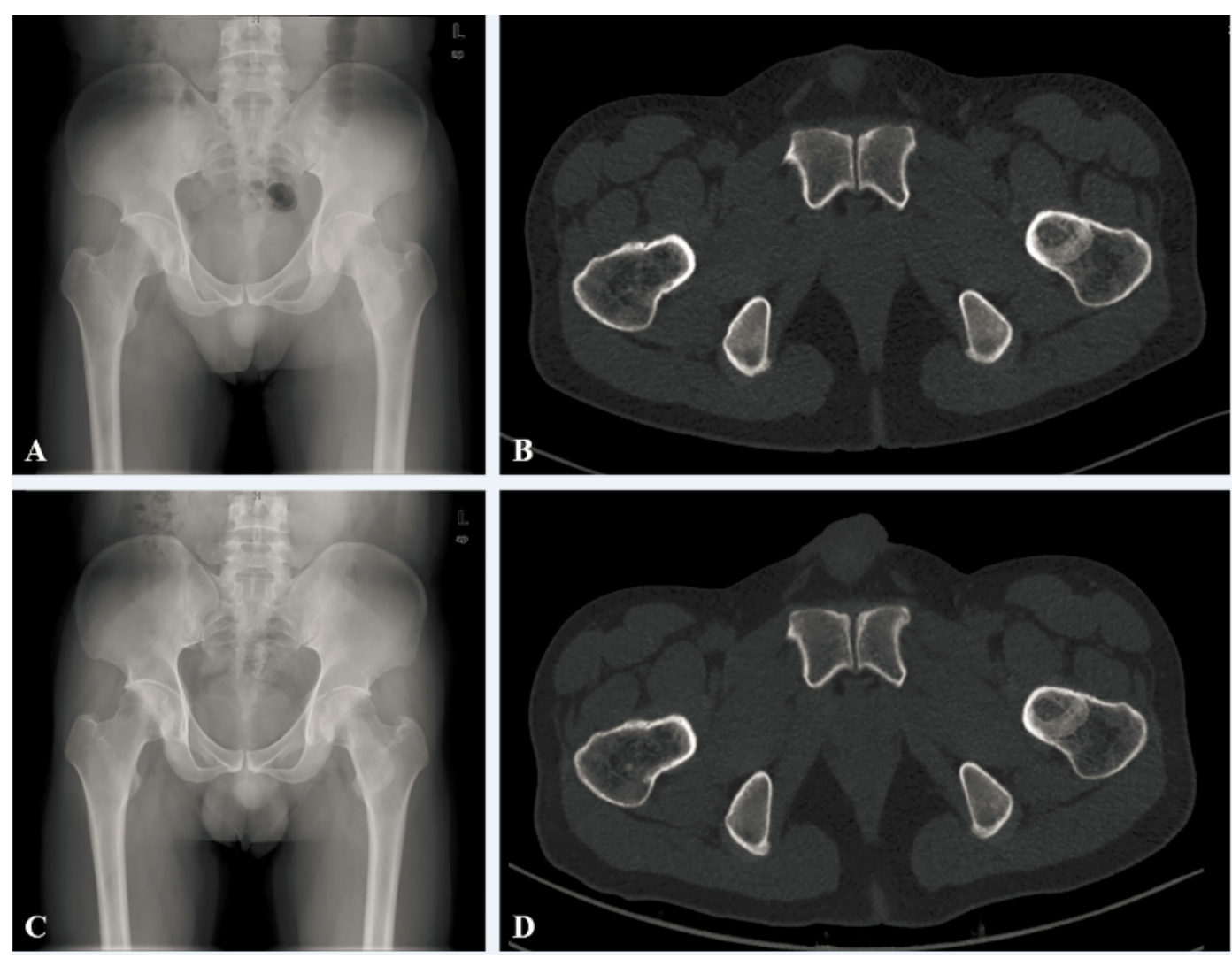

\section{Figure 2}

A and B Type I lesion was present in the left femoral neck with intact cortical bone and calcar. Fig. 2-C and D Type I lesion was latant at the 24-month followup.
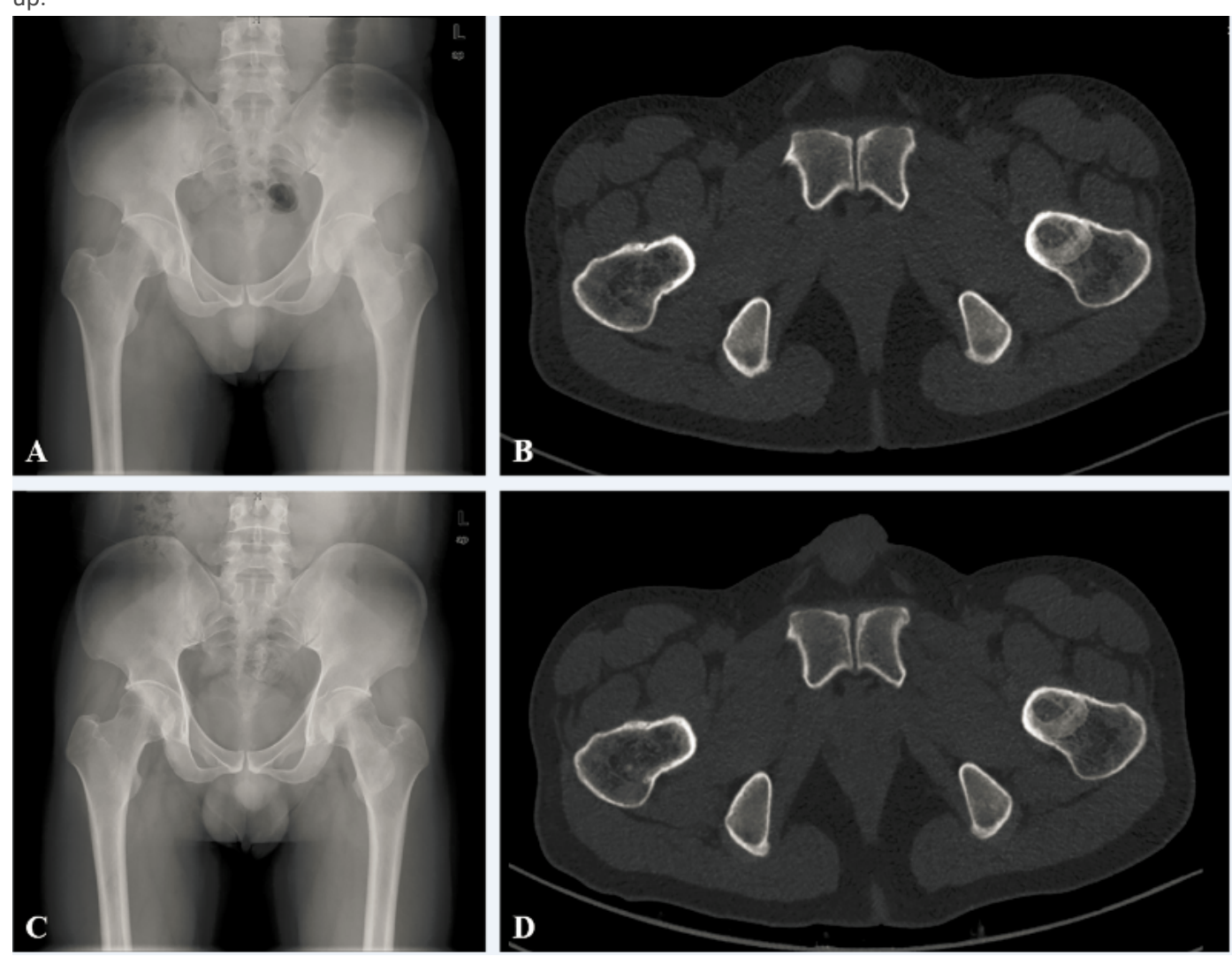

\section{Figure 2}

A and B Type I lesion was present in the left femoral neck with intact cortical bone and calcar. Fig. 2-C and D Type I lesion was latant at the 24-month followup. 

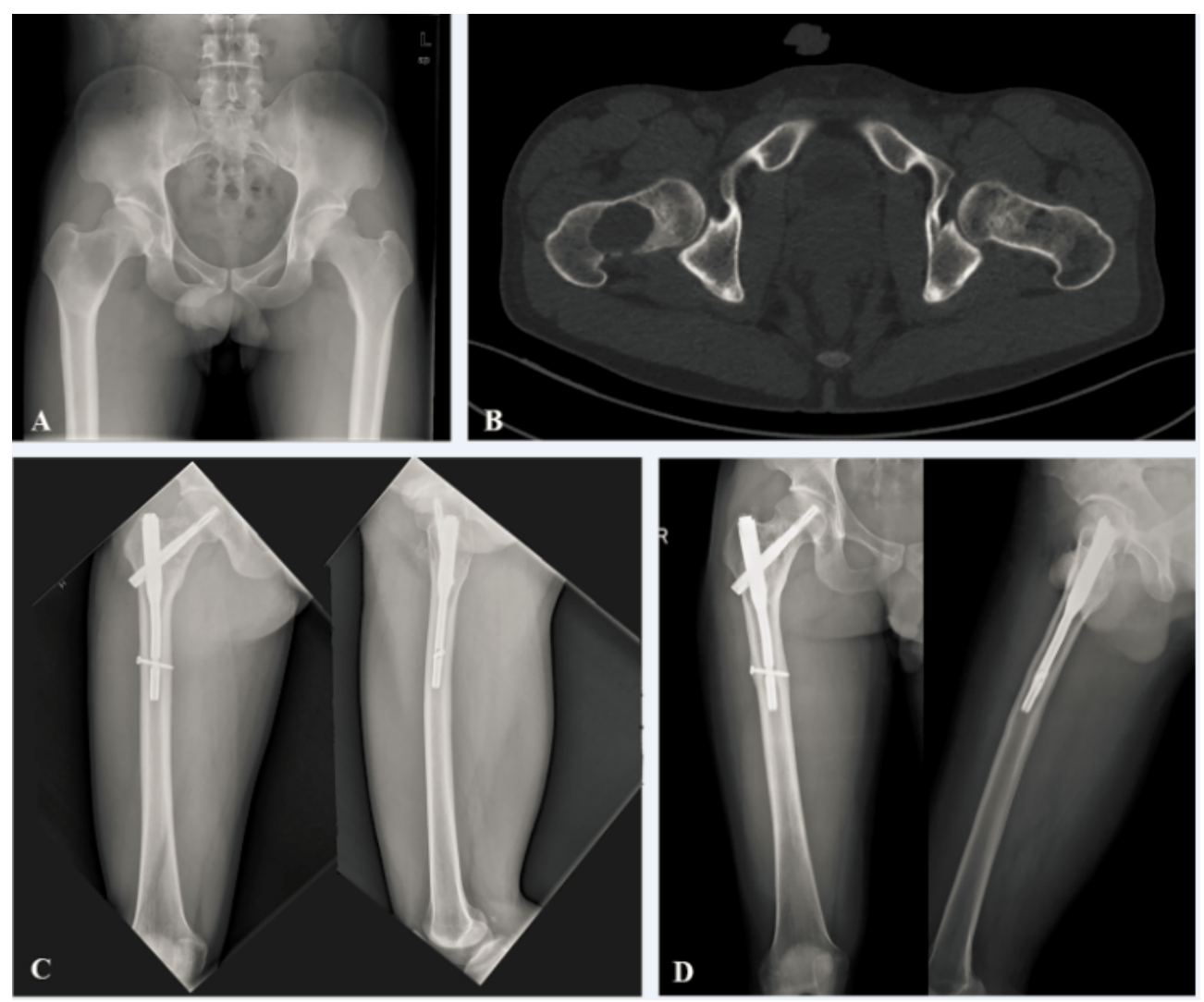

\section{Figure 3}

A Type II lesion. Fig 3-B The extensive bone loss of proximal femur (focal thinning of cortical bone). Fig 3-C 6 months after surgery. Fig 3-D 68-month followup showed no evidence of recurrence of lesion and fracture.
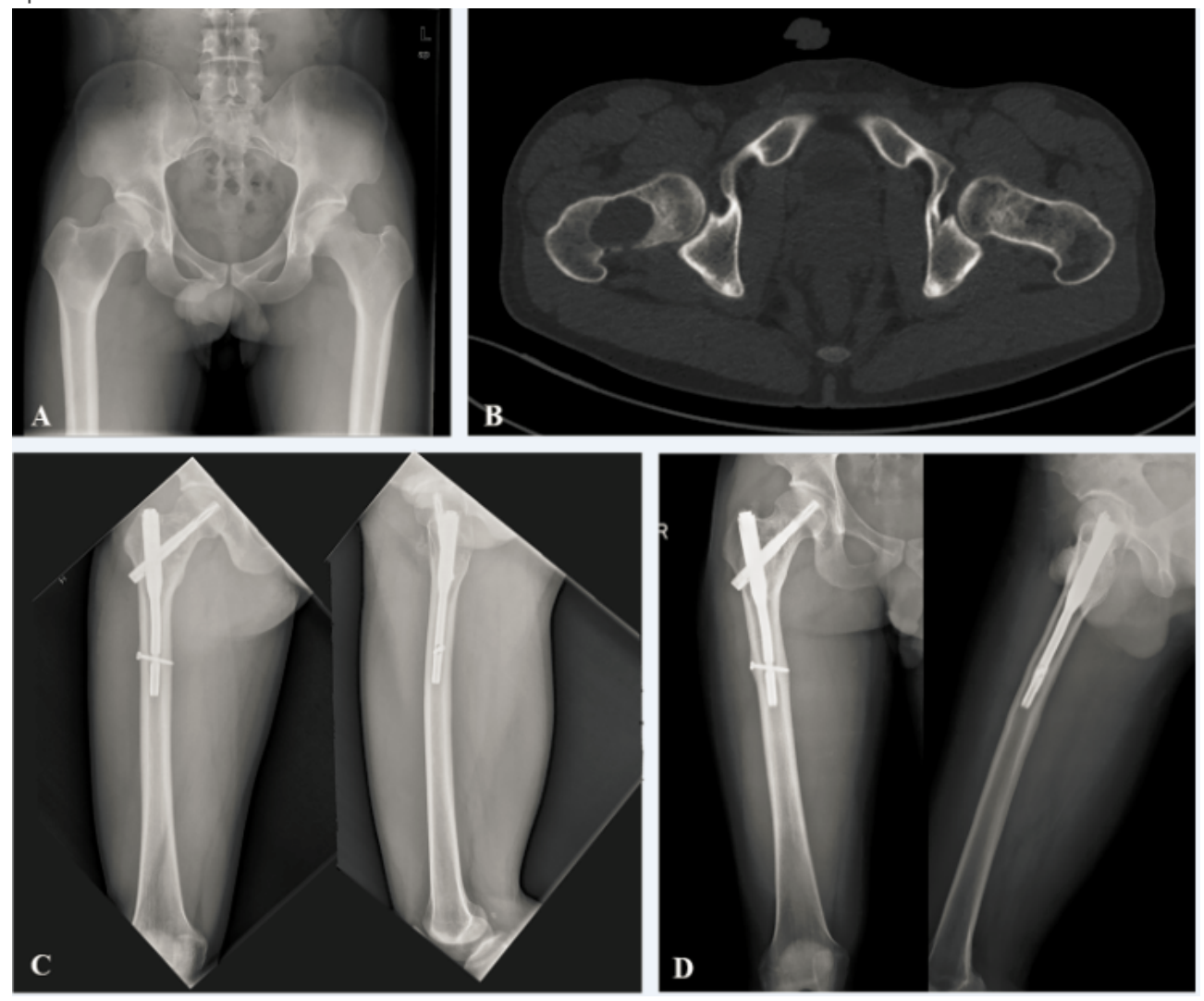

Figure 3 
A Type II lesion. Fig 3-B The extensive bone loss of proximal femur (focal thinning of cortical bone). Fig 3-C 6 months after surgery. Fig 3-D 68-month followup showed no evidence of recurrence of lesion and fracture.

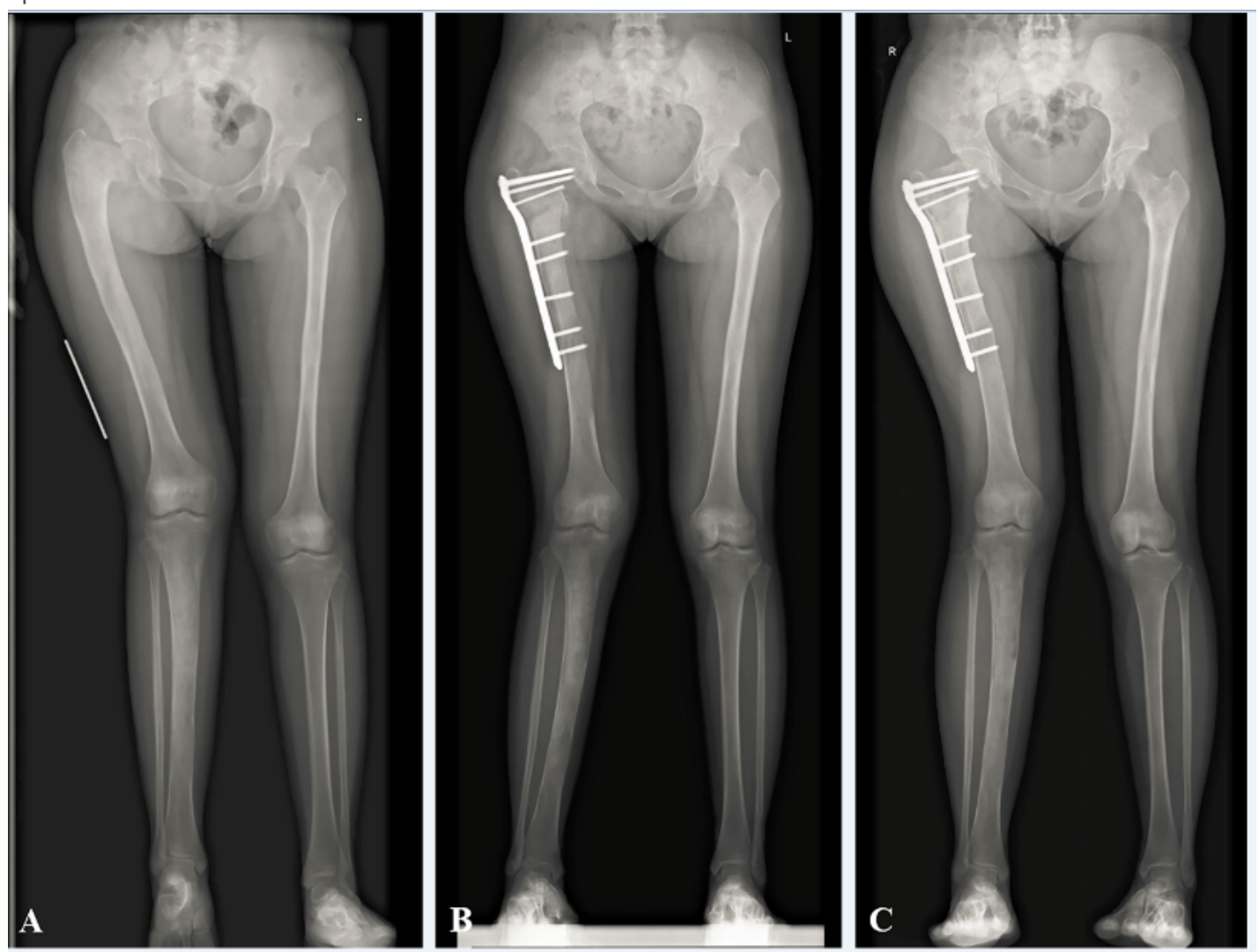

\section{Figure 4}

A Type III lesion with coxa vara. Fig. 4-B 7 month after surgery. Fig. 4-C The radiograph showed no evidence of recurrence of lesion and re-progress of deformity at 24 months.
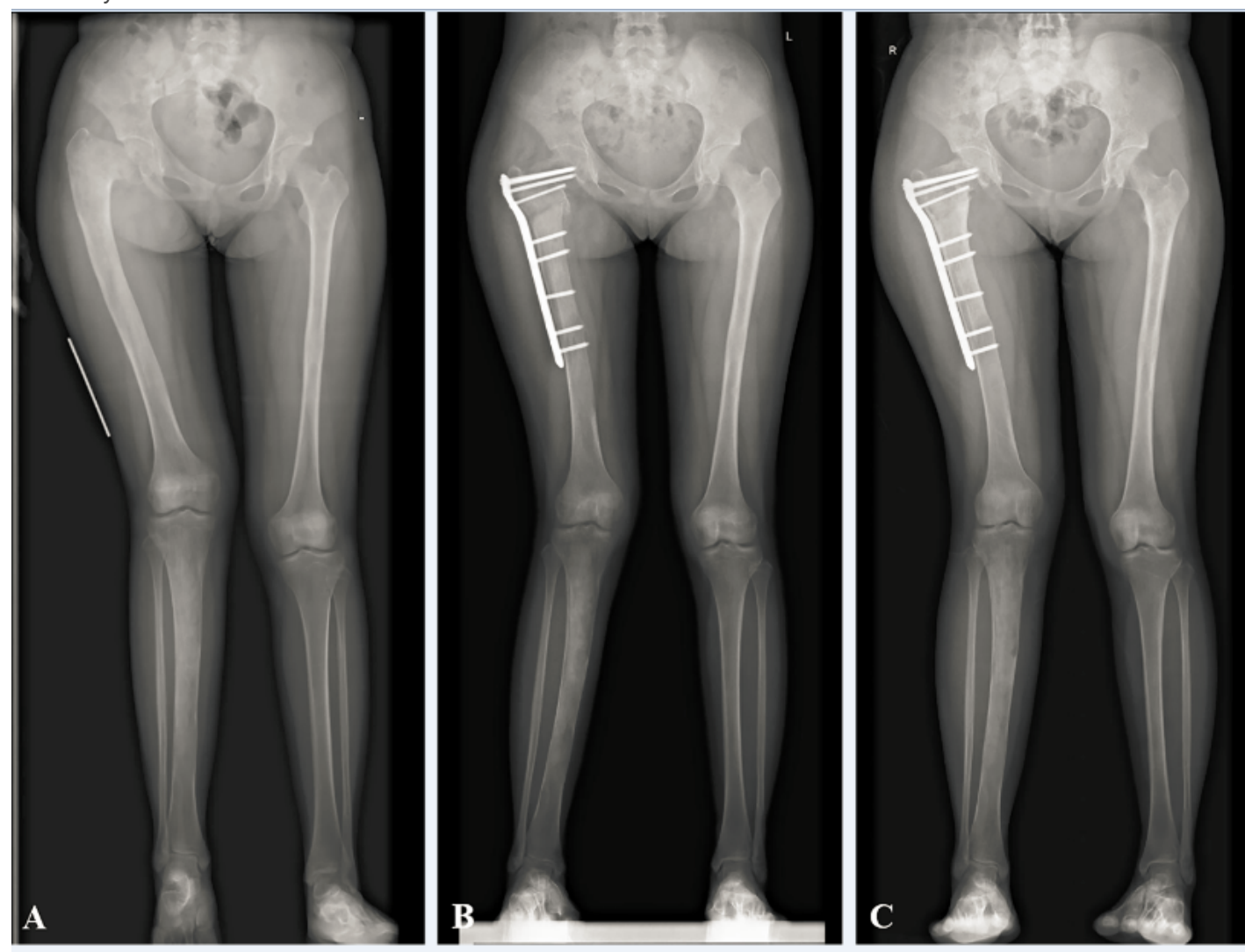

Figure 4 
A Type III lesion with coxa vara. Fig. 4-B 7 month after surgery. Fig. 4-C The radiograph showed no evidence of recurrence of lesion and re-progress of deformity at 24 months.

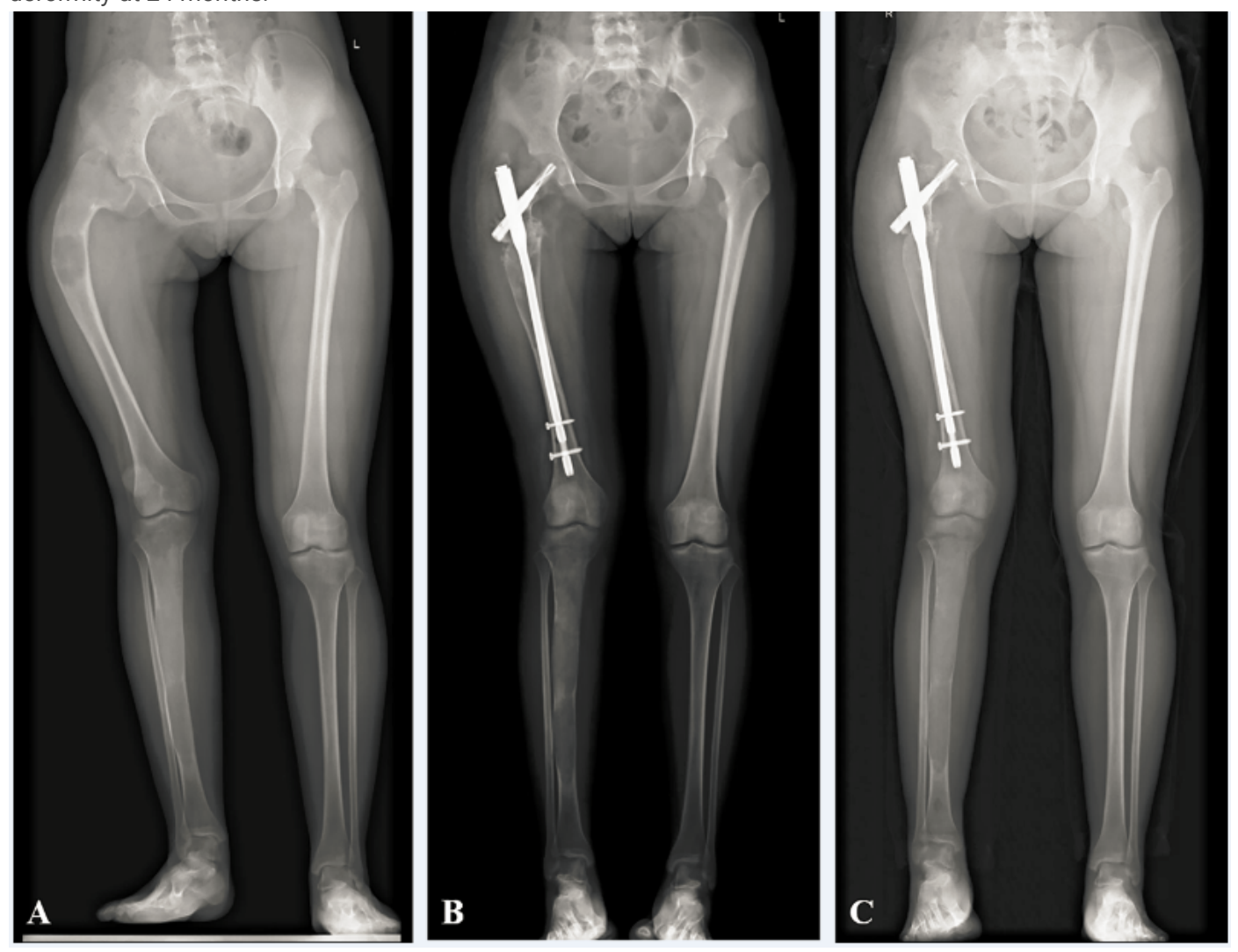

\section{Figure 5}

A Type III lesion. Fig. 5-B The radiograph at 2 months postoperatively. Fig. 5-C The radiograph showed good union of osteotomy site, alignment has been correct, no evidence of recurrence of lesion and re-progress of deformity at 24 months postoperatively.

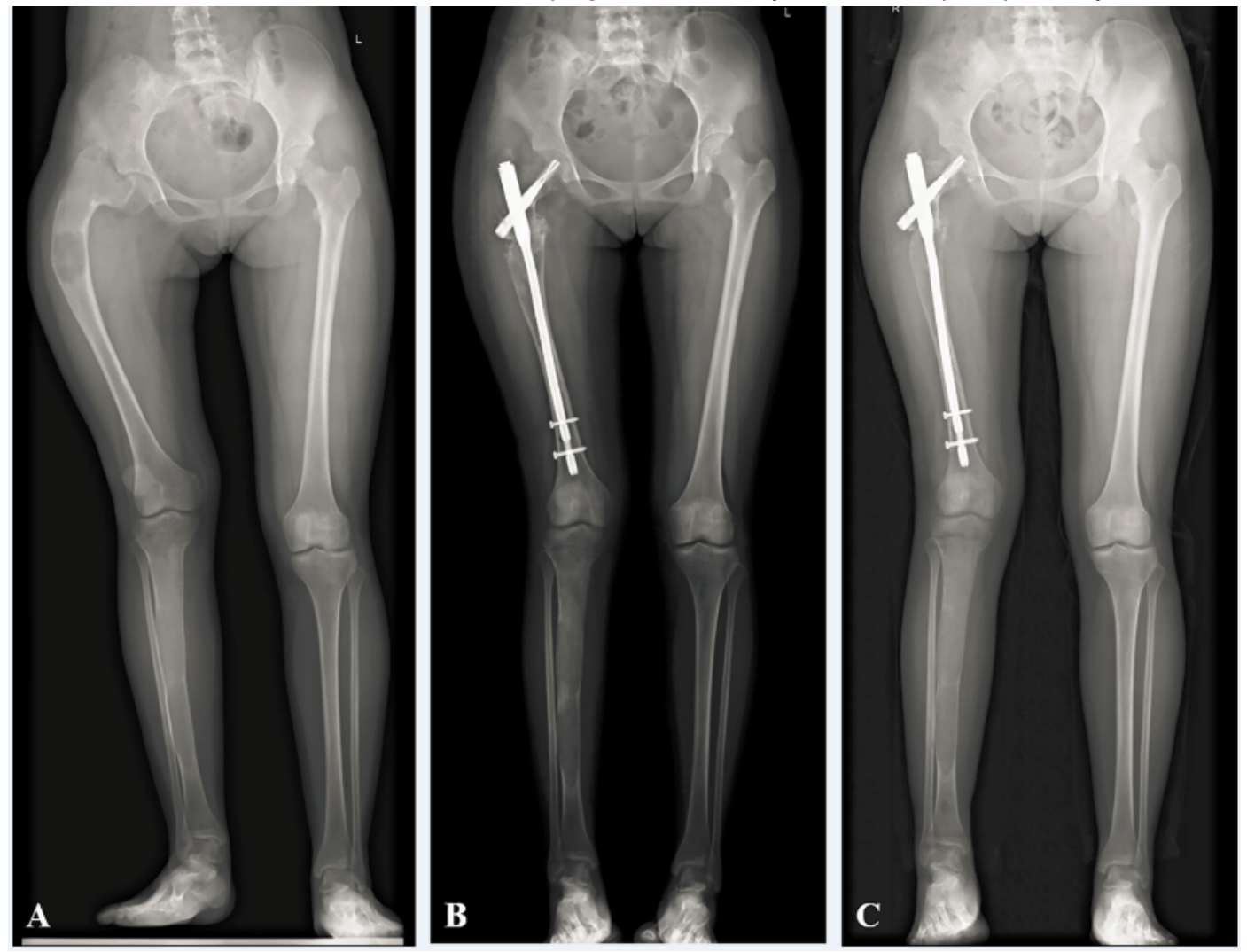

Figure 5 
A Type III lesion. Fig. 5-B The radiograph at 2 months postoperatively. Fig. 5-C The radiograph showed good union of osteotomy site, alignment has been correct, no evidence of recurrence of lesion and re-progress of deformity at 24 months postoperatively.

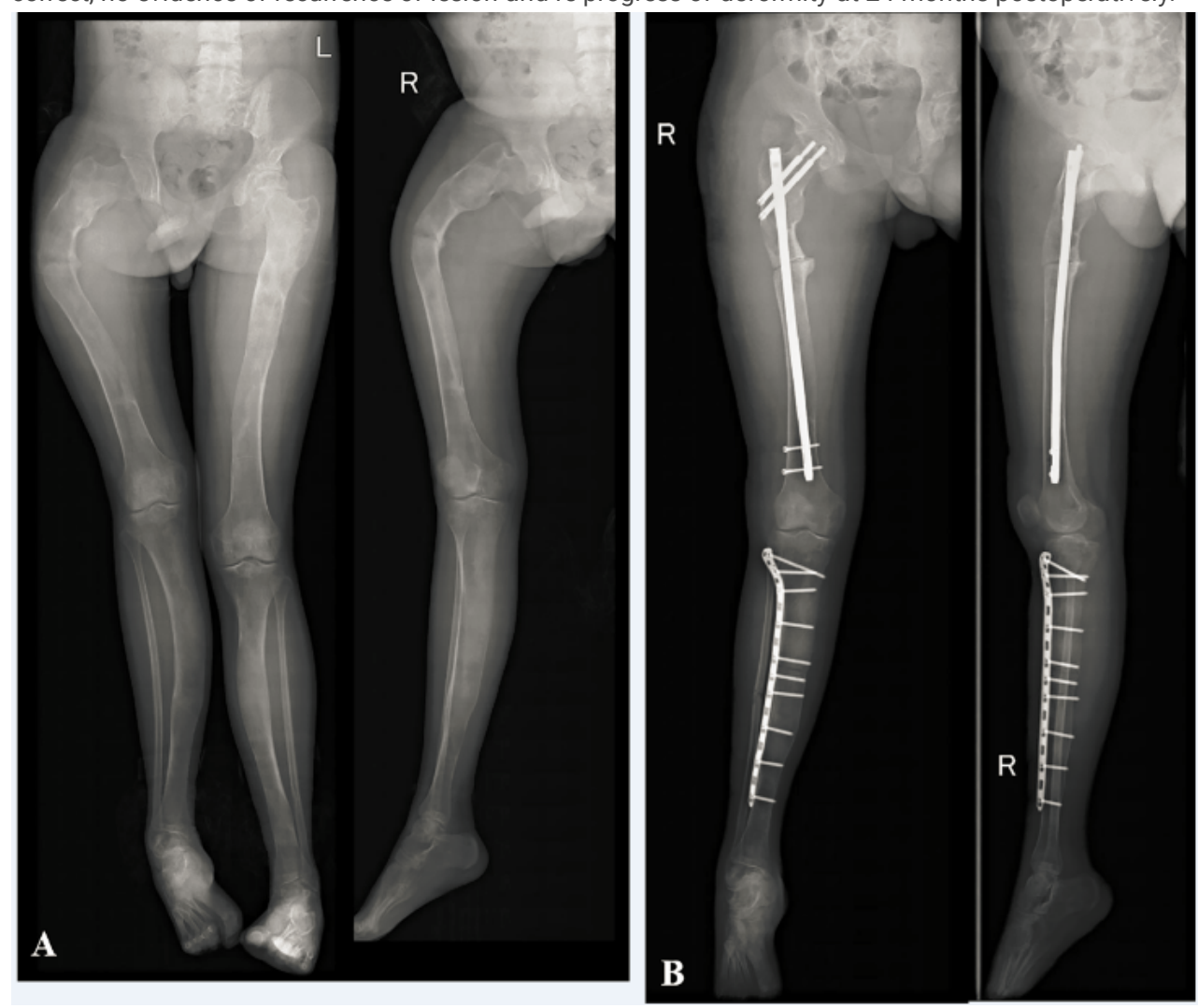

Figure 6

A Type IV lesion was associated with genu valgum. Fig 6-B Tibial valgus osteotomy is performed 3 months after the femoral valgus osteotomy.
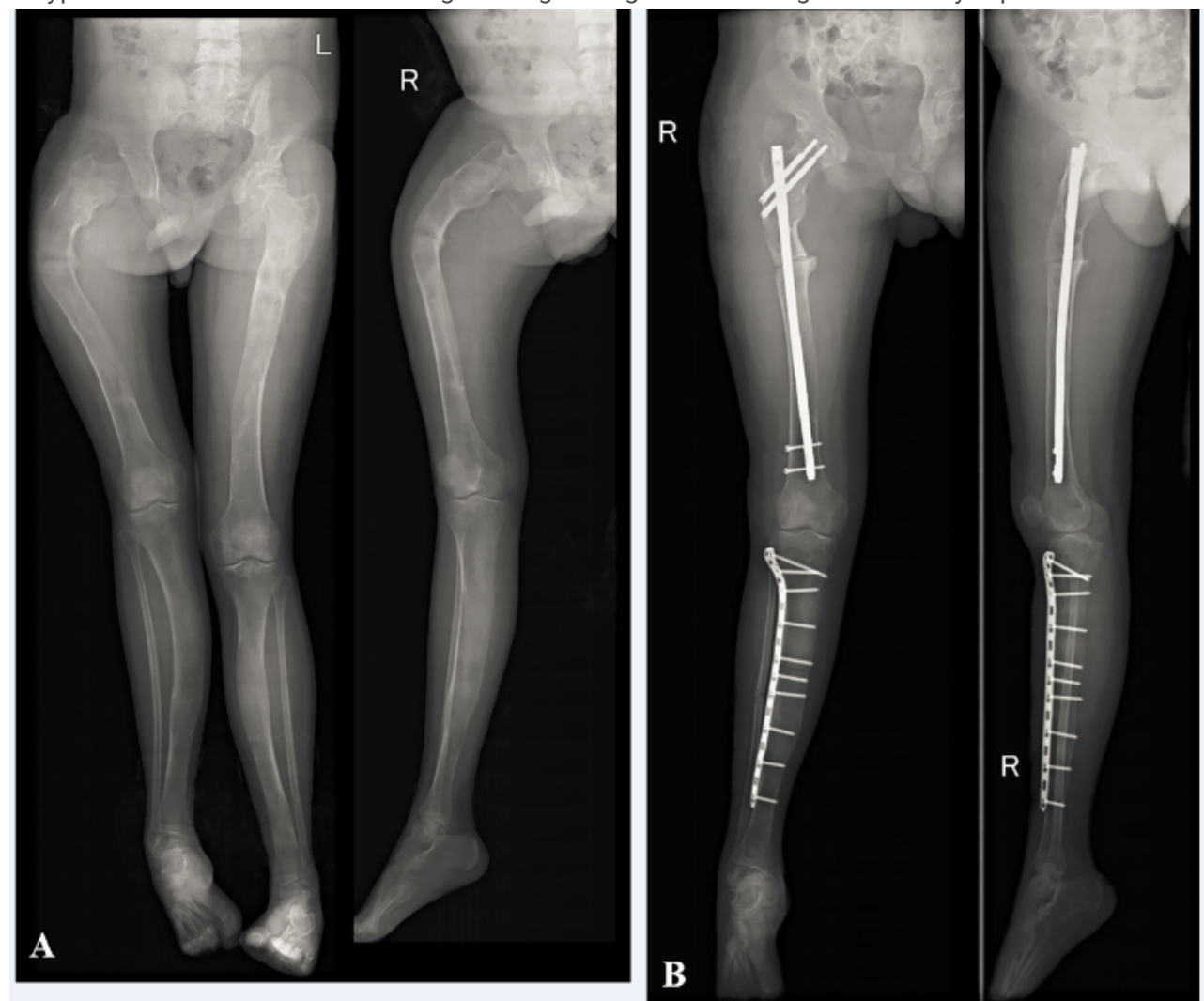

\section{Figure 6}

A Type IV lesion was associated with genu valgum. Fig 6-B Tibial valgus osteotomy is performed 3 months after the femoral valgus osteotomy. 

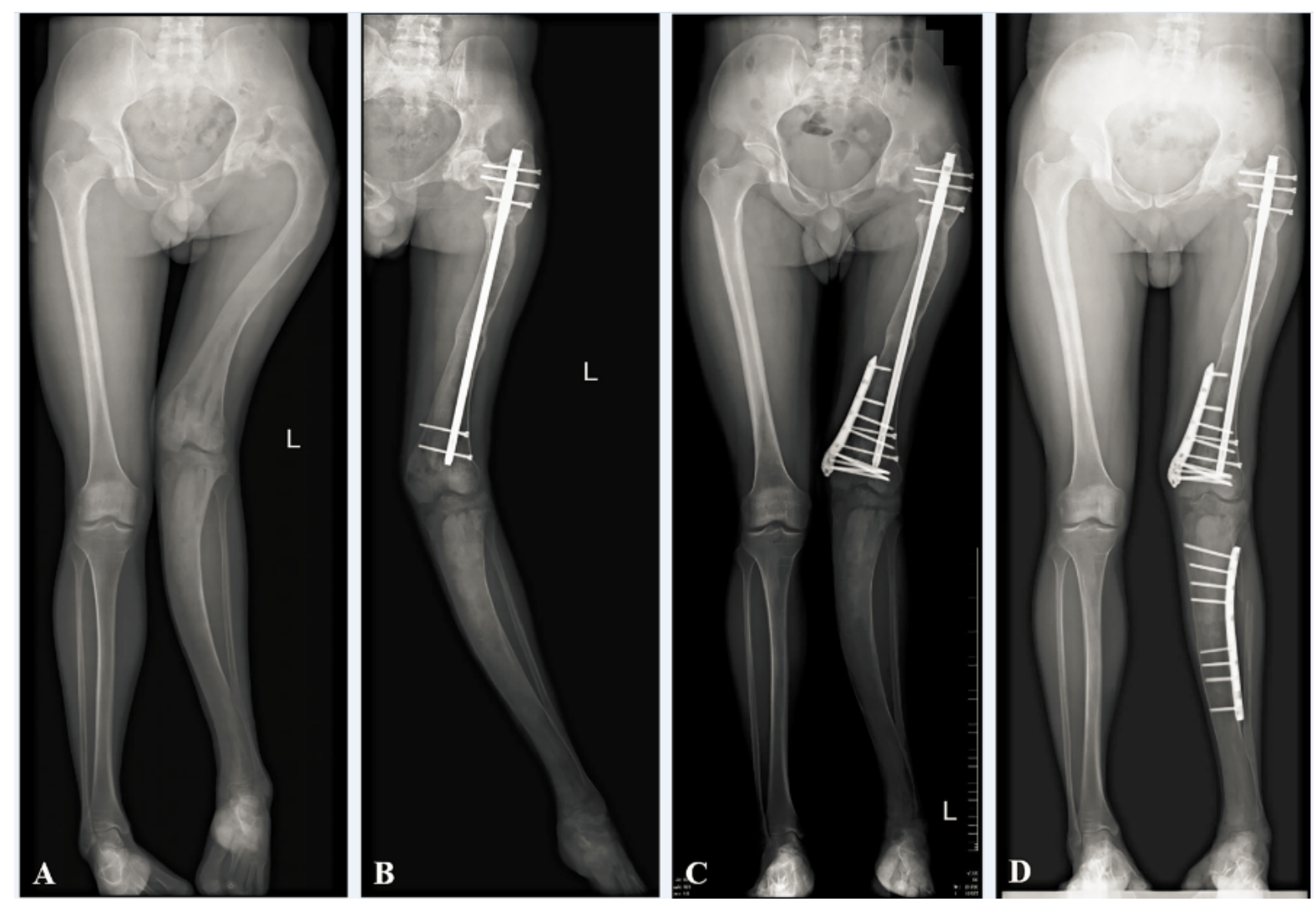

Figure 7

A Type IV lesion was associated with coxa vara, femoral shaft deformity, and genu valgum. Fig 7-B 9 months after the double-level osteotomy. Fig 7-C 21 months after the double-level osteotomy and 10 months after distal femoral osteotomy. Fig 7-D 80 months after the double-level osteotomy, 69 months after distal femoral osteotomy and 59 months after tibial valgus osteotomy.


Figure 7 
A Type IV lesion was associated with coxa vara, femoral shaft deformity, and genu valgum. Fig 7-B 9 months after the double-level osteotomy. Fig 7-C 21 months after the double-level osteotomy and 10 months after distal femoral osteotomy. Fig 7-D 80 months after the double-level osteotomy, 69 months after distal femoral osteotomy and 59 months after tibial valgus osteotomy.

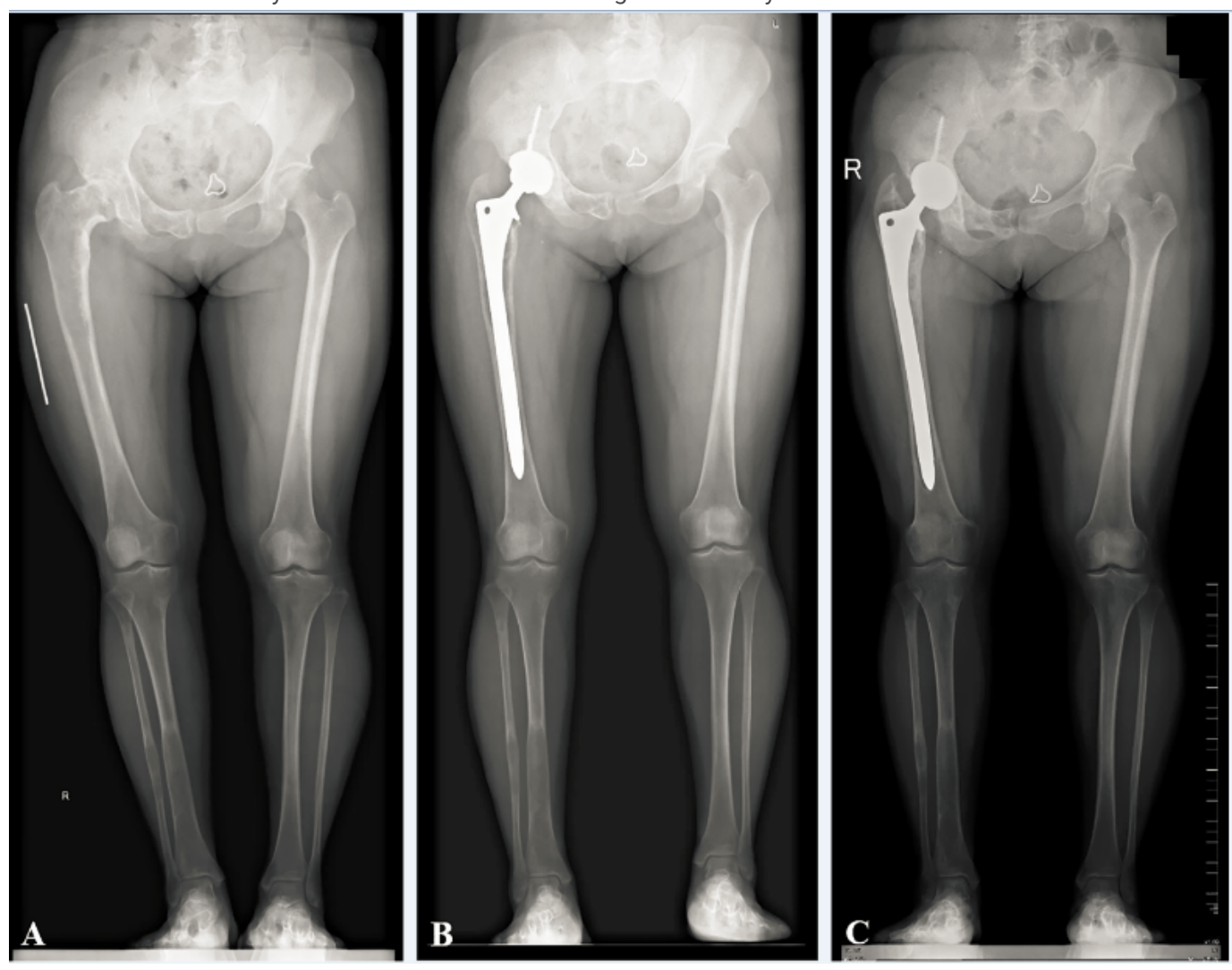

Figure 8

A Type V lesion with arthritis of hip. Fig 8-B 1 month after surgery. Fig 8-C 35 months after surgery.

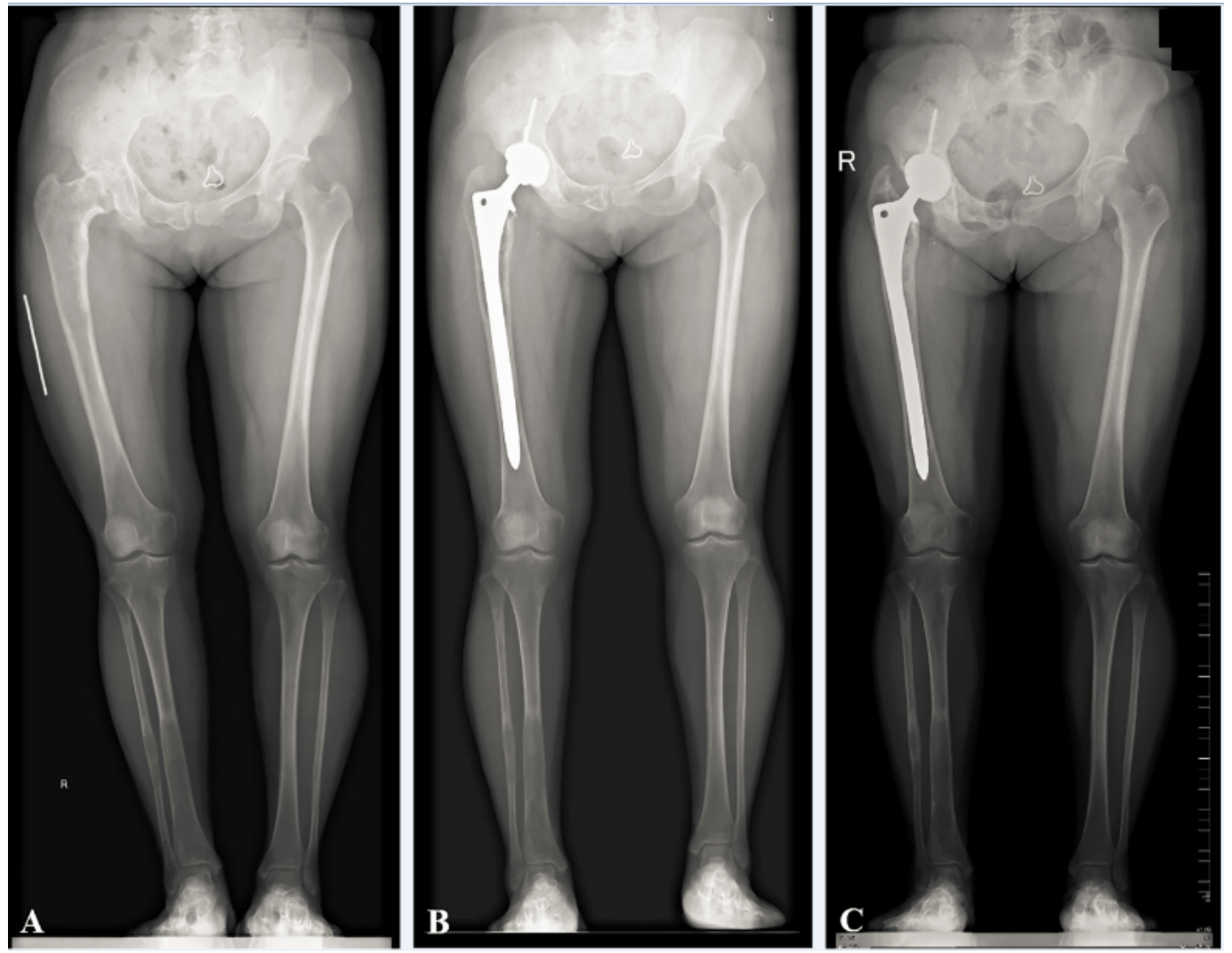

Figure 8 

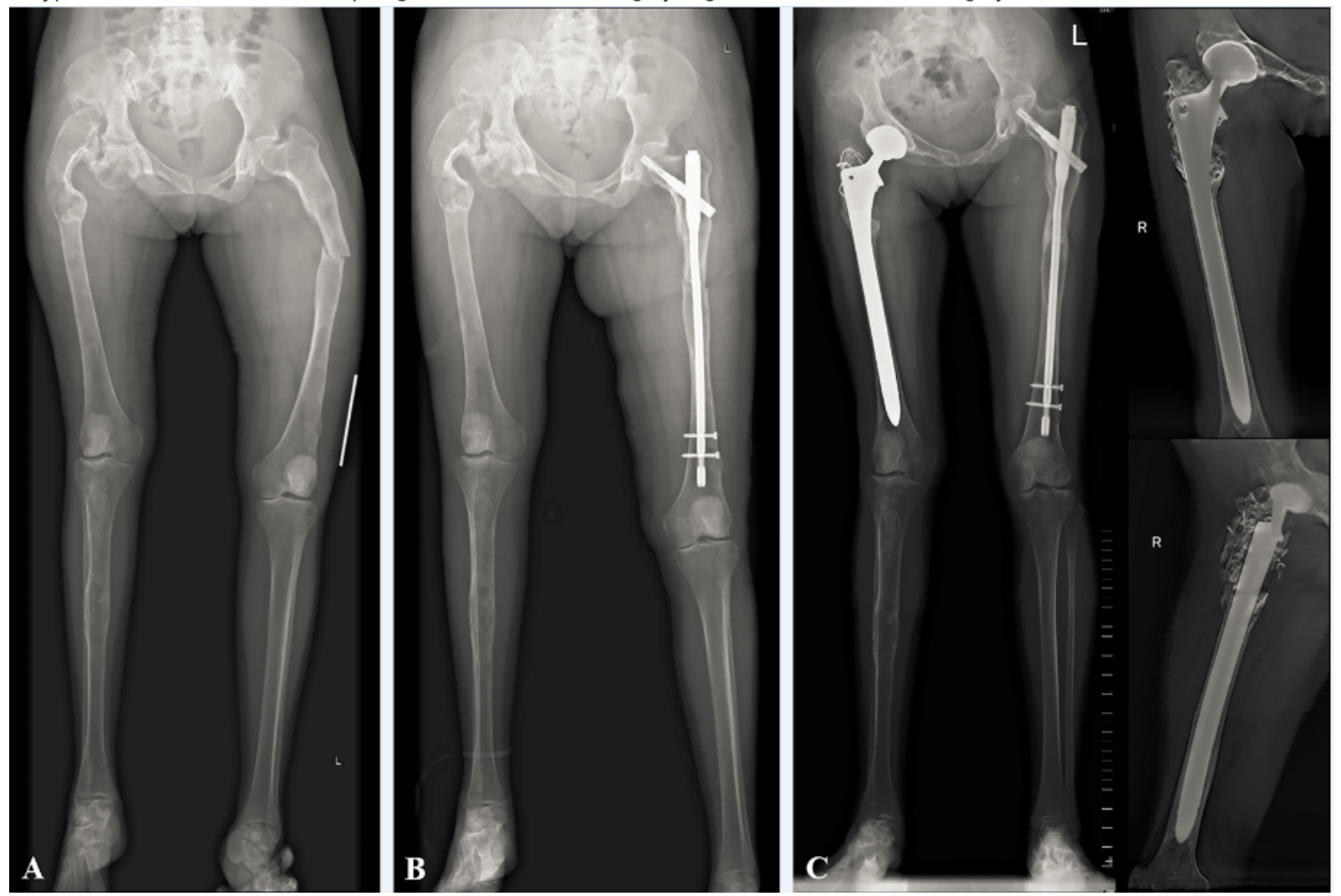

Figure 9

A Type V lesion. Fig 9-B 6 months after internal fixation. Fig 9-C 42 months after total hip arthroplasty.
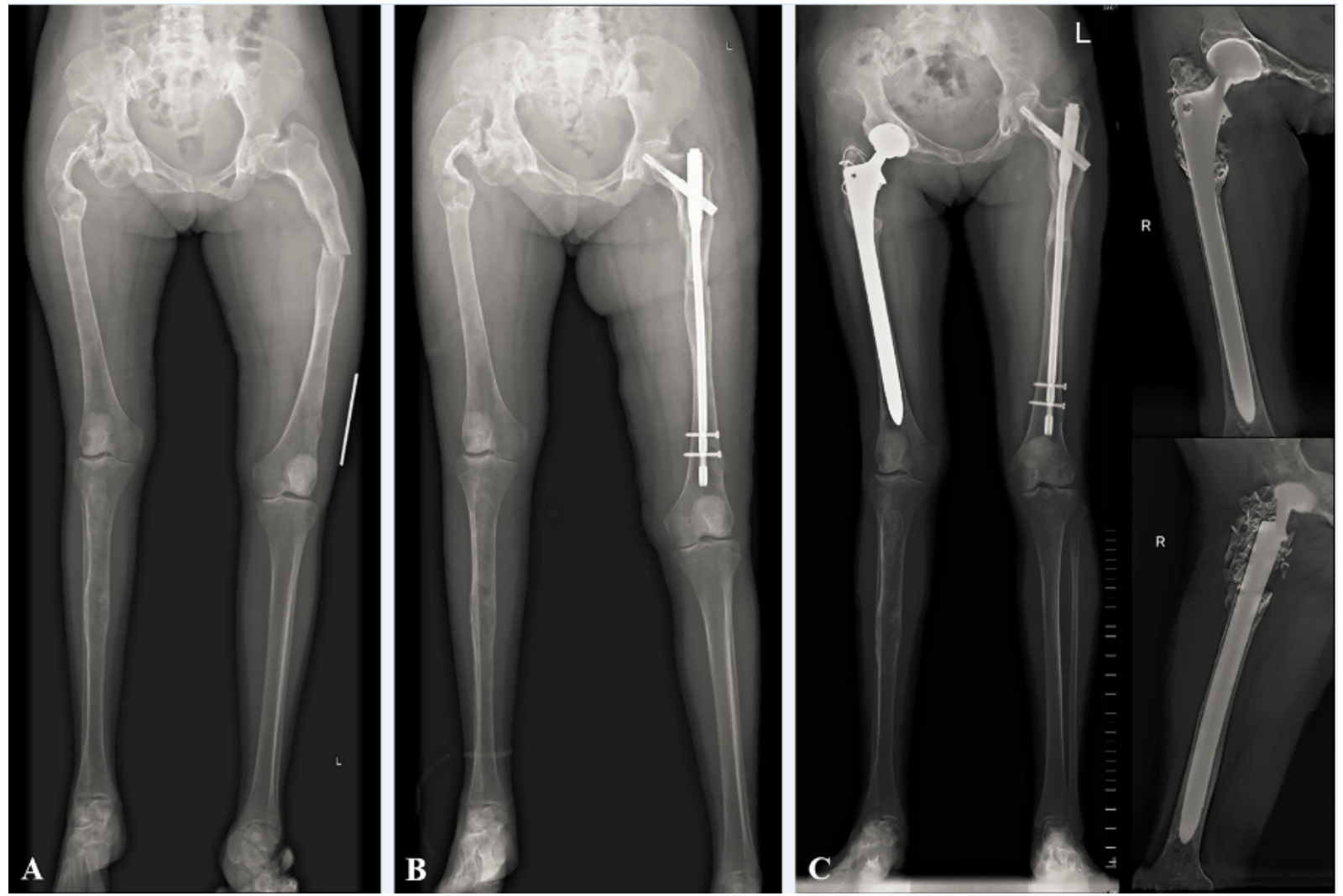

\section{Figure 9}

A Type V lesion. Fig 9-B 6 months after internal fixation. Fig 9-C 42 months after total hip arthroplasty.

Page $17 / 17$ 